\title{
GLOBAL INNOVATION INDEX AND TURKEY'S STATUS AMONG THE NEXT 11 COUNTRIES
}

\author{
Tansu BARKER \\ Brock University, CANADA
}

\begin{abstract}
There has been an increased awareness and appreciation of innovation as a crucial element of business success in the last two decades. The purpose of this paper is to examine the level of innovativeness of Turkey versus eight of the Next 11 (N11) countries. The analysis is based on The Global Innovation Index (GII) that contains some sixty variables confirming that innovation is a multifaceted and complicated concept Rule of law, tertiary enrollment, total $R \& D$ expenditures, information and computer technology (ICT) access and infrastructure are higher for Turkey compared to the other eight countries. Multiple regression analysis, using just political stability and total $R \& D$ expenditures, shows that Turkey is above the eight country average and appears to be in an excellent position to achieve the potential that is attributed to it as an N11 country.
\end{abstract}

Key Words: Global Innovation Index, Next 11 Countries, Political Stability, Turkey

\section{INTRODUCTION}

The concept of innovation is not easy to define (Johannessen, et al., 2001, 20; Harmancioglu et al., 2009, 229). Kotabe and Swan $(1995,622)$ maintain that one of the greatest obstacles to understanding innovation has been the lack of a meaningful measure. Garcia and Calantone $(2002,110)$ report that the terms "radical, incremental, really-new, imitative, discontinuous, architectural, modular, improving, and evolutionary" have been used to define innovation. Notwithstanding the issues of degree of newness, whose perspective and method of achieving it (Johannessen, et al., 2001, 20), most definitions of innovation in the literature have included the concept of newness. For instance, Slappendel $(1996,107)$ asserts that the perception of newness is essential to the concept of innovation as it serves to differentiate innovation from change.

One of the earliest definitions of innovation is provided by Zaltman et al. $(1973,10)$ as "any idea, practice, or material artifact perceived to be new by the relevant unit of adoption". The European Commission's Green Paper $(1995,4)$ defined innovation rather broadly as a synonym for "the successful production, assimilation and exploitation of novelty in the economic and social spheres". Nohria and Gulati $(1996,1245)$ included policy and structure in their definition of innovation based on newness. While all of these definitions serve to highlight an important aspect of innovation, we base our study on the definition that "An innovation is the implementation of a new or significantly improved product (good or service), a new process, a new marketing method, or a new organizational method in business practices, workplace organization, or external relations" as adopted by the Global Innovation Index (GII) developed by INSEAD $(2011,4)$.

In the last two decades, there has been an increased awareness and appreciation of innovation (Drazin and Schoonhoven, 1996, 1065) as a means to create and maintain sustainable competitive advantage and as a key element of business success (Johannessen, et al., 2001, 20). The traditional resource based view maintains that competitive advantage rests on basic core values like quality, cost and timeliness (López, 2005, 663; Lee, 2009, 216). However, as a result of increasing global competitiveness and technological advances, innovation has become an important additional factor in creating and sustaining competitive advantage in a rapidly changing business environment (Johannessen, et al., 2001, 20; Lee, 2009, 216). Unfortunately, managing the risky and complex process of innovation has been challenging (Hollins, 2000, 140; Bueno et al., 2008, 156). 
Different authors have used a variety of factors and approaches to measure innovation and at different levels, such as the firm or the country level. Johannessen et al. $(2001,21)$ have suggested that "the picture that emerges from these diverse approaches underscores the point that a multitude of factors are interacting to induce innovation in economic life". Lee $(2009,216)$ concluded that "although each factor remains important, it is unlikely by itself or as part of a group to provide a sustainable competitive advantage". The GII approach adopted in this study is the simple average of the 1) Input and 2) Output Sub-Indices. The Innovation Input Sub-Index is the simple average of five pillar scores. The five pillars and the composite variables that constitute the Input sub-index are as follows:

- Institutions - Political (3), Regulatory (3), Business Environment (3)

- Human Capital \& Research - Education (5), Tertiary Education (6), R \& D (3)

- Infrastructure - ICT (4), Energy (4), General Infrastructure (3)

- Market Sophistication - Credit (4), Investment (4), Trade \& Competition (5)

- Business Sophistication - Knowledge workers (4), Innovation Linkages (5), Knowledge Absorption (4)

To elaborate, the Institutions pillar is made up of the political, regulatory and environment composite variables. The numbers in brackets represent the individual variables that constitute the composite variable. For example, the political composite variable consists of political stability, government effectiveness and press freedom. The Output sub-index pillar includes the following:

- Scientific Outputs - Knowledge Creation (4), Knowledge Impact (3), Knowledge Diffusion (4)

- Creative Outputs - Creative Intangibles (4), Goods and Services (5)

The Innovation Output Sub- Index is the simple average of the two pillar scores and the overall GII is the simple average of the Input and Output Sub-Indices. Since our purpose is to examine the current level of innovativeness in the N11 (Next 11) countries in terms of their future potential we have decided to exclude the output variables from further consideration.

\section{RESEARCH OBJECTIVE}

Goldman Sachs investment bank identified eleven countries labeled N11 as having a high potential of becoming the world's largest economies in the 21st century, along with the BRICs (Wilson and Stupnytska, 2007). They used five criteria comprising macroeconomic stability, debt to GNP ratio, political maturity, openness to trade and quality of education as projected two decades into the future to identify the following countries: Bangladesh, Egypt, Indonesia, Iran, Mexico, Nigeria, Pakistan, Philippines, S. Korea, Turkey and Vietnam.

While these projections are encouraging for the N11 countries, achievement of this potential depends on making the appropriate economic, political and social decisions starting from the current state of affairs. Goldman Sachs itself declared that they "are conscious of the leap of faith that is needed to believe that this potential might be realized". They have called this undertaking a dream precisely for that reason and confess that for several of the N11, the hurdle is even higher than the BRICKs. Given its importance, understanding where the N11 stand today regarding their innovative capabilities is useful. In particular, we are interested in the relative position, the strengths and weaknesses of Turkey in terms of innovativeness relative to the other N11 countries. Therefore, the purpose of this manuscript is to examine the level of innovativeness of the N11 countries and to compare them to Turkey, which is a member of G20 and N11.

\section{GLOBAL INNOVATION INDEX ANALYSIS}

Examination of the GII and the N11 countries revealed that considering all of them together might be impractical as Bangladesh and South Korea represent significant outlier characteristics along most dimensions. Hence, we decided to exclude from further analyses S. Korea and Bangladesh that are 
ranked first and last among the N11 countries. The GII values for the remaining 9 countries are presented in Table 1, where XTR represents the eight countries without Turkey.

The GII for Turkey is very significant $(\mathrm{p}=.006)$ compared with the average for the eight remaining N11 countries. While this result is encouraging for Turkey in terms of innovation as well as the potential it holds for the future of the country, it would be useful to disaggregate the GII and assess some of its components. However, recognizing that the Input sub-index comprises some 60 variables across 15 composite variables makes the task daunting and perhaps unnecessarily complicated for our purposes. At this point, we are guided by the construction of the globalization index that uses practical proxies to calculate it. Furthermore, the small number of countries in our sample also necessitates identifying a small group of parsimonious variables. Consequently, we have selected 12 variables based on the collective judgment of several colleagues who are experienced teachers of international marketing and other international courses. The resulting 12 variables and the statistics for Turkey and the other countries are presented in Table 2.

(*) Significant at $\mathrm{p}=.005$

Only five of the 12 selected variables are significant $(p=.005)$ in comparing Turkey and the other eight countries. The significant variables, all of which are higher for Turkey, are rule of law, tertiary enrollment, total R\&D expenditures, information and computer technology (ICT) access and infrastructure. Enrollment at tertiary institutions as a percentage of the young population, total R\&D expenditures and access to ICT are very crucial inputs to trigger innovation. These advantages coupled with the general facilitating role of infrastructure and rule of law furnish Turkey with significant advantages over the other eight countries. However, R\&D expenditures by business and university and business collaboration as well as high tech imports do not enhance Turkey's position and decisive steps should be taken to improve them. Especially, R\&D expenditures by business and collaboration between universities and business are vital to increase a country's innovation capacity. According to Mikl-Horke, $(2004,100)$ institutions of education play a great role in promoting the acceptance of innovations in a country. While R\&D expenditures by business are driven by the availability of funds as much as the prevailing business culture, collaboration between business and universities should be less dependent on funding to achieve. In our view, this is more a matter of strategy and creating an atmosphere of willingness to appreciate each other's existing strengths rather than funding. We might cautiously suggest that the first fruitful steps might be taken by business rather than the universities that need to have both a theoretical as well as practical orientation in their research. Jeong-dong and Park, (2006, 1049) have found that financial support from government in the early stages of R\&D and collaboration with universities improves the chances of success. In their taxonomy of globalization of innovation, Archibugi and Iammarino (1999, 320) propose that innovations are developed based on nationally or globally produced technology or through global collaboration. They suggest that, regardless of the process of innovation, public policy plays an important role.

These findings indicate certain strengths and possible areas of improvement for Turkey and the other eight countries collectively. The concern in this analysis is the inability to assign weights or a degree of importance to these variables as the GII itself is calculated using "simple averages". In the next section, we will attempt to represent GII as a function of selected variables with weights attached to them.

\section{WEIGHTS OF THE SELECTED VARIABLES}

So far, the weight of each variable is assumed to be equal as a function of calculating the GII based on "simple averages". Within the context of determining priorities and setting an innovation strategy lead by the government, it is useful to determine the relative weights of the important variables in managing GII. This is especially important in the nine N11 countries selected in this paper in terms of laying the foundation to achieve the "dream" of future success.

To determine the relative weights of the GII variables, we used multiple regression analysis where GII is a function of the 12 selected variables for all nine countries involved. After many iterations and 
combinations of variables, the most meaningful equation (Table 3) that emerged with the highest adjusted $\mathrm{R}^{2}$ and the smallest number of significant variables is:

GII $=23.71+.23 *\{$ Pol. Stability $\}+.3 *\{$ Total R\&D Expenditure $\}$

ANOVA of this equation yielded a very satisfactory $F=12.5$ with a significance level of $p=.01$. The levels of $\mathrm{R}^{2}=.83$ and adjusted $\mathrm{R}^{2}=.77$ are also acceptable for our purposes in an exploratory study of this nature. Political stability is the more important variable in this equation compared to total R\&D expenditure based on the higher beta value. In fact, political stability is so important that it would yield an adjusted $\mathrm{R}^{2}=.58$ by itself. It should be noted that if total $\mathrm{R} \& \mathrm{D}$ expenditures are removed, the next variable to enter the equation would be ICT access with a lower adjusted $\mathrm{R}^{2}=.71$. Overall, we are satisfied with the levels of explanation, significance and the small number of variables in this equation. Next, we will calculate the new GII for the nine countries and examine the results.

Table 3 - Multiple Regression Results

\begin{tabular}{|l|l|c|c|c|c|}
\hline \multicolumn{2}{|l|}{ Model } & Coefficient & $\boldsymbol{\beta}$ & $\mathbf{t}$ & Sig. \\
\hline \multirow{3}{*}{} & (Constant) & 23.71 & & 14.794 & .000 \\
\cline { 2 - 6 } & Political Stability & .23 & 1.062 & 4.991 & .004 \\
\cline { 2 - 6 } & R\&D Expenditure (Total) & .3 & .520 & 2.444 & .058 \\
\hline
\end{tabular}

\section{GII BASED ON TWO VARIABLES}

The GII values based on the multiple regression equation for the eight countries are presented in Table 4. Matched pairs analysis showed that the difference between the original GII values (mean $=29.87$ ) and the calculated GII (mean $=30.06$ ) is not significant. They are also highly and significantly correlated $\left(\mathrm{r}^{2}=.85, \mathrm{p}=.004\right)$. These results provide additional confirmation beyond the adjusted $\mathrm{R}^{2}$ (.77) that the multiple regression equation is a reasonable alternative for GII for this group of countries with the additional benefit of providing variable weights.

Turkey is slightly above the eight country average (32.38 vs. 30.34$)$ with an important total R\&D expenditure advantage over the average (14.4 vs. 6.26) and the other countries except for Iran. Unfortunately, Turkey's reported political stability score does not enhance its GII standing, especially relative to Vietnam. Improvements in this area would go a long way in increasing Turkey's GII position and provide further optimism in achieving its potential as suggested by its inclusion among the N11 countries. However, we acknowledge that especially the political stability scores are approximately 2 years old and do not reflect the recent developments in these countries. In particular, the political stability index, as determined by the World Bank (2010) using 9 different sources, is quite volatile on an annual basis. It covers a range from 31.7 to the low figure of 18.9 (in 2009) for Turkey from 2005 to 2009. For instance, just replacing the lowest figure in 2009 with the 5-year average (24.4) would increase Turkey's score from 34.1 to 35.3. Notwithstanding the usual difficulties and shortcomings of constructing any index, the significant differences in these variables identify areas of success as well as characteristics that require close attention and improvement.

(o) R\&D expenditure for Nigeria is unknown and has been excluded.

\section{CONCLUSIONS}

The only country with a GII higher than Turkey based on the multiple regression results is Vietnam. Hence, we decided to inspect the nature of GII between Turkey and Vietnam across several variables. Vietnam is leading Turkey in exports of goods and services, including high-tech goods, university and business collaboration and political stability. Turkey is ahead of Vietnam in employment in knowledge-intensive services, $R \& D$ expenditures in total and by business, expected school attendance, tertiary enrollment, ICT access, rule of law and infrastructure. As vital inputs for innovation, employment in knowledge-intensive services, R\&D expenditures in total and by business, expected school attendance, tertiary enrollment and ICT access are very encouraging. The role of 
infrastructure as part of the macro environment is especially stimulating to business and should facilitate exports further coupled with R\&D expenditures.

In conclusion, Turkey appears to be in an excellent position to achieve the potential that is attributed to it by the Global Innovation Index (GII) (INSEAD, 2011). It is well ahead of the eight other N11 countries taken as a group. It is also in a much better position than Vietnam along most of the important dimensions of innovation that are covered in this study. Turkey is poised to pull well ahead of Vietnam if it harnesses its existing advantages. It seems the real challenge for Turkey among the N11 nations is to replicate the accomplishment of South Korea, which was not included in this study. 


\section{REFERENCES}

Archibugi, D. and Iammarino, S., (1999), The Policy Implications of The Globalisation of Innovation, Research Policy, 28. 2, 3, pp. 317-336.

Bueno, E., Anton, J. M. R. and Salmador, M. P., (2008), Knowledge Creation as a Dynamic Capability: Implications for Innovation Management and Organisational Design, International Journal of Technology Management, 41 (1/2), pp. 155-168.

Drazin, R. and Schoonhoven, C.B., (1996), Community, Population, and Organization Effects on Innovation: A Multilevel Perspective, Academy of Management Journal, 39 (5), pp. 1065-1083.

European Commission, (1995), Green Paper on Innovation, Brussels. http://europa.eu/ documents /comm/green_papers/pdf/com95_688_en.pdf.

Garcia, R. and Calantone, R.J., (2002), A Critical Look at Technological Innovation Typology and Innovativeness Terminology: A Literature Review, Journal of Product Innovation Management, 19 (2), pp. 110-132.

Harmancioglu, N., Droge, C. and Calantone, R., (2009), Theoretical Lenses and Domain Definitions in Innovation Research, European Journal of Marketing, 43 (1/2), pp. 229-263.

Hollins, B. (2000), Why the Resistance to Long-Term Innovation Management?, International Journal of Innovation Management, 4 (2), pp. 135-148.

INSEAD, (2011), http://www.globalinnovationindex.org/gii/main/analysis/ rankings.cfm \#CGI.SCRIPT_NAME\#

Jeong-dong, L., and Park, C., (2006), Research and Development Linkages in a National Innovation System: Factors Affecting Success and Failure In Korea, Technovation 26 (9), pp. 1045-1054.

Johannessen, J., Olsen, B. and Lumpkin, G.T., (2001), Innovation as Newness: What is New, How New, and New to Whom?, European Journal of Innovation Management, 4 (1), pp.20-31.

Kotabe, M. and Swan, K.S., (1995), The Role of Strategic Alliances in High Technology New Product Development, Strategic Management Journal, 16 (8), pp. 621-636.

Lee, S., (2009), Developing Hierarchical Structure for Assessing the Impact of Innovation Factors on a Firm's Competitiveness - A Dynamic-Capabilities Approach, Journal of American Academy of Business, 15 (1), pp. 216-223.

López, S. V., (2005), Competitive Advantage and Strategy Formulation: The Key Role of Dynamic Capabilities, Management Decision, 43 (5), pp. 661-669.

Mikl-Horke, G., (2004), Globalization, transformation and the Diffusion of Management Innovations, Journal for East European Management Studies, 9 (2), pp. 98-122.

Nohria, N. and Gulati, R., (1996), Is Slack Good or Bad For Innovation?, Academy of Management Journal, 39 (5), pp. 1245-64.

Slappendel, C., (1996), Perspectives on Innovation in Organizations, Organization Studies, 17 (1), pp. 107-129.

Wilson, D. and Stupnytska, A., (2007), The N11: More Than An Acronym, Global Economics Paper No: 153, Goldman Sachs Economic Research.

World Bank, (2009), http://info.worldbank.org.

Zaltman, G., Duncan, R. and Holbek, J., (1973), Innovations and Organizations, Wiley, NY. 